\title{
Asymmetric Dimethylarginine versus Proton Pump Inhibitors Usage in Patients with Stable Coronary Artery Disease: A Cross-Sectional Study
}

\author{
Olga Kruszelnicka ${ }^{1, *}$, Jolanta Świerszcz ${ }^{2}$, Jacek Bednarek ${ }^{3}$, Bernadeta Chyrchel ${ }^{2}$, \\ Andrzej Surdacki ${ }^{2,+}$ and Jadwiga Nessler ${ }^{1,+}$ \\ 1 Department of Coronary Artery Disease and Heart Failure, Jagiellonian University Medical College and \\ John Paul II Hospital, 80 Prądnicka, 31-202 Cracow, Poland; jnessler@interia.pl \\ 2 Second Department of Cardiology, Jagiellonian University Medical College and University Hospital, \\ 17 Kopernika, 31-501 Cracow, Poland; grasshoppers@interia.eu (J.Ś.); chyrchelb@gmail.com (B.C.); \\ surdacki.andreas@gmx.net (A.S.) \\ 3 Department of Electrocardiology, John Paul II Hospital, 80 Prądnicka, 31-202 Cracow, Poland; \\ bednareks@op.pl \\ * Correspondence: olga.kruszelnicka@onet.pl; Tel.: +48-501-510-400 \\ $\dagger$ Joint senior authors on this work.
}

Academic Editor: Michael Henein

Received: 30 January 2016; Accepted: 22 March 2016; Published: 15 April 2016

\begin{abstract}
A recent experimental study suggested that proton pump inhibitors (PPI), widely used to prevent gastroduodenal complications of dual antiplatelet therapy, may increase the accumulation of the endogenous nitric oxide synthesis antagonist asymmetric dimethylarginine (ADMA), an adverse outcome predictor. Our aim was to assess the effect of PPI usage on circulating ADMA in coronary artery disease (CAD). Plasma ADMA levels were compared according to PPI use for $\geqslant 1$ month prior to admission in 128 previously described non-diabetic men with stable CAD who were free of heart failure or other coexistent diseases. Patients on PPI tended to be older and with insignificantly lower estimated glomerular filtration rate (GFR). PPI use was not associated with any effect on plasma ADMA (0.51 \pm 0.11 (SD) vs. $0.50 \pm 0.10 \mu \mathrm{mol} / \mathrm{L}$ for those with PPI $(n=53)$ and without PPI $(n=75)$, respectively; $p=0.7$ ). Additionally, plasma ADMA did not differ between PPI users and non-users stratified by a history of current smoking, CAD severity or extent. The adjustment for patients' age and GFR did not substantially change the results. Thus, PPI usage does not appear to affect circulating ADMA in non-diabetic men with stable CAD. Whether novel mechanisms of adverse PPI effects on the vasculature can be translated into clinical conditions, requires further studies.
\end{abstract}

Keywords: asymmetric dimethylarginine; coronary artery disease; proton pump inhibitors

\section{Introduction}

Proton pump inhibitors (PPI) - widely used to prevent gastroduodenal complications of dual antiplatelet therapy - have recently been demonstrated to raise intracellular levels of asymmetric dimethylargininie (ADMA), an endogenous inhibitor of nitric oxide (NO) synthesis, which was accompanied by a lower NO formation, depressed endothelium-mediated vasorelaxation in vitro and increased circulating ADMA by about $20 \%$ in mice. These effects were ascribed to a PPI-dependent direct inhibition of the activity of the major ADMA-degrading enzyme type 1 dimethylarginine dimethylaminohydrolase (DDAH-1) [1].

Because ADMA is a recognized adverse outcome predictor in coronary artery disease (CAD) patients [2-4], the PPI-ADMA interaction might contribute to an excessive cardiovascular risk in patients on PPI irrespective of the use of antiplatelet agents including clopidogrel, or a prior 
history of myocardial infarction [5-11]. Importantly, an elevated risk of myocardial infarction was associated with the usage of PPI but not $\mathrm{H}_{2}$-receptor antagonists also in the general population subjects, mainly without aspirin or clopidogrel, which may suggest an underlying mechanism not directly involving either platelet aggregation or changed drug absorption due to a rise in gastric $\mathrm{pH}[11,12]$. Admittedly, potential negative clinical impacts of PPI on the risk of adverse cardiovascular events are still controversial [13] with conflicting results between randomized trials and observational studies $[10,14]$. Nevertheless, the proposed mechanistic concept [1] was not confirmed in a recent placebo-controlled, open-label, cross-over study where PPI administration for four weeks was not associated with significant effects on plasma ADMA or flow-dependent vasodilation in adults [15].

Therefore, our aim was to estimate the effect of PPI usage on circulating ADMA in stable CAD.

\section{Results}

Clinical and angiographic characteristics according to PPI use are shown in Table 1. Patients taking a PPI prior to admission (mainly omeprazole $20 \mathrm{mg}$ o.i.d. or pantoprazole $20 \mathrm{mg}$ o.i.d.) tended to be older and with lower estimated glomerular filtration rate (GFR).

Table 1. Characteristics of CAD patients according to PPI use prior to admission on a background of concomitant low-dose aspirin, ACEI and statin.

\begin{tabular}{|c|c|c|c|}
\hline Characteristic & Patients on PPI $(n=53)$ & Patients without PPI $(n=75)$ & $p$-Value \\
\hline Age (years) & $59 \pm 11$ & $56 \pm 10$ & 0.12 \\
\hline Body-mass index $\left(\mathrm{kg} / \mathrm{m}^{2}\right)$ & $27.7 \pm 3.6$ & $27.4 \pm 3.5$ & 0.6 \\
\hline History of current smoking, $n(\%)$ & $16(30 \%)$ & $20(27 \%)$ & 0.8 \\
\hline Multivessel CAD, $n(\%)$ & $41(77 \%)$ & $54(72 \%)$ & 0.6 \\
\hline CAD extent score & $31(21-44)$ & $28(19-40)$ & 0.5 \\
\hline Left ventricular ejection fraction (\%) & $70 \pm 7$ & $68 \pm 6$ & 0.2 \\
\hline Hypertension, $n(\%)$ & $43(80 \%)$ & $56(75 \%)$ & 0.4 \\
\hline Mean blood pressure (mm Hg) & $96 \pm 11$ & $95 \pm 10$ & 0.7 \\
\hline Estimated GFR $\left(\mathrm{mL} / \mathrm{min}\right.$ per $\left.1.73 \mathrm{~m}^{2}\right)$ & $69 \pm 9$ & $72 \pm 11$ & 0.09 \\
\hline LDL cholesterol $(\mathrm{mmol} / \mathrm{L})$ & $2.8 \pm 0.7$ & $2.8 \pm 0.6$ & 0.8 \\
\hline HDL cholesterol (mmol/L) & $0.9 \pm 0.3$ & $1.0 \pm 0.3$ & 0.2 \\
\hline Triglycerides (mmol/L) & $1.4 \pm 0.6$ & $1.5 \pm 0.7$ & 0.3 \\
\hline Glucose $(\mathrm{mmol} / \mathrm{L})$ & $5.8 \pm 0.9$ & $5.7 \pm 0.8$ & 0.5 \\
\hline High-sensitivity C-reactive protein (mg/L) & $1.9(1.1-4.0)$ & $1.8(1.0-3.8)$ & 0.8 \\
\hline
\end{tabular}

Data are shown as mean $\pm \mathrm{SD}$, median (interquartile range) or $n(\%) ; p$-values by 2-tailed Student's $t$-test or Mann-Whitney $U$ test, and chi-squared test for proportions. CAD: coronary artery disease; ADMA: asymmetric dimethylarginine; ACEI: angiotensin-converting enzyme inhibitors; GFR: glomerular filtration rate calculated according to the Modification of Diet in Renal Disease study formula; HDL: high-density lipoproteins; LDL: low-density lipoproteins; PPI: proton pump inhibitors.

The use of PPI was not associated with any effect on plasma ADMA (Table 2). In addition, there were no interactions between PPI use and the categorized potential confounders, i.e., current smoking, angiographic CAD severity or extent in terms of plasma ADMA $(p>0.3)$, so that ADMA levels did not differ between PPI users and PPI non-users stratified by a history of current smoking, the presence of multivessel CAD or an over-median Sullivan score of angiographic CAD extent (Table 2). Adjustment for patients' age and GFR by means of ANCOVA did not substantially change the results. 
Table 2. Plasma ADMA levels according to PPI use prior to admission.

\begin{tabular}{cccc}
\hline & \multicolumn{2}{c}{ ADMA before Admission $(\mu \mathbf{m o l} / \mathbf{L})$} & \multirow{2}{*}{$\boldsymbol{p}$-Value } \\
\cline { 2 - 3 } & PPI Users $(\boldsymbol{n = 5 3 )}$ & PPI Non-Users $(\boldsymbol{n}=\mathbf{7 5})$ & \\
\hline All CAD subjects, $n=128$ & $0.51 \pm 0.11$ & $0.50 \pm 0.10$ & 0.7 \\
\hline History of current smoking & & & \\
Yes, $n=36$ & $0.51 \pm 0.11$ & $0.50 \pm 0.10$ & 0.4 \\
No, $n=92$ & $0.51 \pm 0.10$ & $0.51 \pm 0.11$ & 0.8 \\
\hline Severity of angiographic CAD & & & 0.7 \\
One-vessel disease, $n=33$ & $0.48 \pm 0.10$ & $0.49 \pm 0.10$ & 0.9 \\
Multivessel disease, $n=95$ & $0.52 \pm 0.11$ & $0.51 \pm 0.11$ & \\
\hline Extent of angiographic CAD & & & 0.6 \\
Sullivan extent score $\leqslant 29, n=65$ & $0.48 \pm 0.09$ & $0.49 \pm 0.10$ & 0.3 \\
Sullivan extent score $>29, n=63$ & $0.54 \pm 0.11$ & $0.52 \pm 0.10$ & \\
\hline
\end{tabular}

Data are shown as mean \pm SD; $p$-values by 2-tailed Student's $t$-test. Abbreviations as in Table 1.

\section{Discussion}

Our salient finding was a similar plasma level of ADMA in PPI users and non-users. This observation appears inconsistent with the previously reported ability of PPI to augment ADMA accumulation in vitro and in an animal model through a direct inhibition of DDAH-1 [1], an enzyme influencing circulating ADMA [16-19]. On the other hand, in subjects with a history of vascular disease, Ghebremariam et al. [15] observed a more pronounced trend towards higher ADMA while on PPI compared to placebo in an interventional cross-over study, nevertheless the differences did not reach the statistical significance, which is in agreement with our cross-sectional retrospective analysis. To the best of our knowledge, our study is the second clinical report on ADMA levels in relation to PPI use.

\subsection{Mechanistic Considerations}

There are several potential explanations of these apparent discrepancies. First, all the patients were receiving angiotensin-converting enzyme inhibitors (ACEI), aspirin and statins, all of which had been previously shown to lower ADMA levels [20-22], thereby obscuring the putative influence of PPI on ADMA. On the other hand, ADMA concentrations in our patients were only slightly lower than ADMA levels measured by the same enzyme-linked immunosorbent assay (ELISA) in control groups of largely untreated subjects of similar age from European populations and without evidence of atherosclerotic vascular disease [23-25], which argues against the proposed explanation and strengthens our findings.

Second, even if the PPI-DDAH-1 interaction took place in vivo, its effects on plasma ADMA could be attenuated or nullified by an effective counter-regulatory mechanism. This hypothetical mechanism might involve any of the recognized determinants of circulating ADMA levels including DDAH-mediated ADMA degradation, urinary ADMA excretion, the activity of type I protein-arginine $\mathrm{N}$-methyltransferases (PRMTs-I), proteolysis rate of proteins with dimethylated arginine residues, and interorgan ADMA transport [26]. Of note, Becker et al. [27] described depressed nicotinamide adenine dinucleotide phosphate (NADPH)-dependent superoxide release and augmented expression of the antioxidant defense enzyme type 1 heme oxygenase (HO-1) in human endothelial cells exposed for 8-24 h to lansoprazole at final concentrations as low as $30 \mu \mathrm{mol} / \mathrm{L}$, i.e., similar to PPI levels $(20 \mu \mathrm{mol} / \mathrm{L})$ that increased intracellular ADMA concentrations by about $30 \%$ via DDAH-1 inhibition as shown by Ghebremariam et al. [1]. The PPI-dependent HO-1 induction occurred at the level of transcription [27], in contrast to PPI direct effects on DDAH-1 activity [1], which can probably further potentiate the former effect in subjects on chronic PPI therapy. Accordingly, because oxidative stress stimulates PRMTs-I expression [28] and inhibits DDAH activity [29,30], the PPI-mediated decrease in endothelial superoxide formation [27] could possibly indirectly downregulate ADMA formation and 
enhance ADMA degradation, thus counteracting the ADMA-increasing effect of the direct DDAH-1 inhibition by PPI [1].

Third, findings from animal experiments cannot be simply extrapolated to clinical conditions because the presence of atherosclerotic cardiovascular disease and risk factors may interfere with ADMA-regulating pathways. Nevertheless, in our hands, there were no significant interactions between PPI use and angiographic CAD extent or severity in terms of plasma ADMA and the results did not substantially change upon exclusion of current smokers from the analysis.

\subsection{Study Limitations}

First, a retrospective study design constrains conclusions drawn from our data. Second, our findings would be strengthened if we also assessed characteristics previously linked to adverse cardiovascular effects of PPI, i.e., magnesium or homocysteine (due to a putative PPI-induced vitamin $\mathrm{B}_{12}$ deficiency), and platelet response to aspirin (attributable to reduced aspirin absorption at a higher intragastric $\mathrm{pH}$ ). Nevertheless, chronic PPI therapy is unlikely to induce clinically relevant changes in serum magnesium [31], vitamin $B_{12}$ or homocysteine [32]. With regard to aspirin antiplatelet effect, contradictory results were reported in patients on a low-dose aspirin treated with concomitant PPI [33,34] and no involvement of ADMA in this interaction [33] has been demonstrated so far. Third, coexistent diseases could affect our results, although we applied a wide range of exclusion criteria to limit the heterogeneity of the study population. Finally, PPI pharmacokinetics is profoundly modulated by genetic loss-of-function polymorphisms of cytochrome P450 (CYP) 2C19 isoform. Compared to so-called extensive metabolizers with both wild-type CYP2C19 alleles, poor mobilizers (those with both mutated CYP2C19 alleles) exhibit elevated circulating PPI levels, e.g., after oral omeprazole its peak plasma level was about 5-fold higher and the area under the concentration-time curve approximately 9-fold higher [35]. Admittedly, we did not perform either genetic or epigenetic testing. However, our aim was to compare ADMA in relation to PPI use in real-world clinical practice irrespective of genotype status. Additionally, the frequency of CYP2C19 poor metabolizers in Caucasian populations averages only about $2 \%-3 \%[36,37]$.

\section{Materials and Methods}

\subsection{Patients}

We performed an additional analysis of the dataset including ADMA levels and clinical and angiographic characteristics of stable CAD men who had previously been described [38]. The study subjects were free of heart failure or diabetes and exhibited the presence of $\geqslant 1$ significant epicardial coronary stenosis on elective coronary angiography in our tertiary-care center [38]. All the patients were receiving a low-dose aspirin, ACEI and statin for at least 3 months prior to the hospitalization. As described previously [38], a wide set of exclusion criteria had been applied, including significant valvular heart disease, infections within previous 2 months, relevant coexistent diseases (e.g., severe renal insufficiency) and chronic non-cardiovascular medication with non-selective non-steroidal anti-inflammatory drugs or coxibs. Out of 151 CAD patients 23 were excluded from the current analysis due to missing data with regard to PPI use for $\geqslant 1$ month before the index hospitalization.

In line with the Declaration of Helsinki, the study protocol was approved by the Bioethics Committee of the Jagiellonian University (Approval numbers: KBET/63/B/2006 dated 27 April 2006 and KBET/364/B/2012 dated 20 December 2012) and informed consent was obtained from the patients, as mentioned previously [38].

\subsection{Procedure}

A sample of peripheral venous blood was collected into ethylenediaminetetraacetic acid tubes in the fasting state in the morning prior to coronary angiography and plasma was kept frozen at $-70^{\circ} \mathrm{C}$ for subsequent biochemical analyses. 
ADMA levels were measured by a commercially available ELISA (DLD Diagnostika GmbH., Hamburg, Germany) — as reported in detail [38] — and compared between 2 subgroups of the study subjects divided on the basis of a history of PPI use for $\geqslant 1$ month before blood sampling on admission for ADMA assay. In addition, we compared ADMA levels in PPI users and non-users according to a history of current smoking, angiographic CAD severity (multivessel vs. one-vessel CAD) [39] and CAD extent quantified by means of the Sullivan score representing a percentage of the vessels with vascular wall irregularities on coronary angiography [40].

\subsection{Statistical Analysis}

Data have been presented as means \pm SD (standard deviation) or medians (interquartile range) for continuous characteristics with normal and non-normal distribution, respectively. The concordance with a Gaussian distribution was checked by the Lilliefors' test. The patients were compared according to PPI use by 2-tailed Student's $t$-test or Mann-Whitney $U$ test, and chi-squared test for continuous and categorical characteristics, respectively. According to a post hoc power calculation for the study group as a whole, the study design allowed to detect a difference in plasma ADMA between PPI users $(n=53)$ and non-users $(n=75)$ of $0.05 \mu \mathrm{mol} / \mathrm{L}(0.5 \mathrm{SD})$ with a power of $80 \%$ at a type I error rate of 0.05 .

In order to test whether an effect of PPI use on circulating ADMA levels was modified by selected categorized covariates, a two-way analysis of variance (ANOVA) was performed to assess these potential interactions with plasma ADMA as a dependent variable and 2 independent factors: PPI use on the one hand and - on the other hand - a history of self-reported current smoking or angiographic CAD severity (multivessel vs. one-vessel CAD) or dichotomized CAD extent (an over-median ( $>29)$ vs. below-median $(\leqslant 29)$ Sullivan score) as a coexistent factor; then an interaction between these factors was estimated. In addition, analysis of covariance (ANCOVA) was used to adjust for continuous clinical characteristics, for which the $p$-value in a univariate comparison between patients with and without PPI did not exceed 0.15 . A $p$-value below 0.05 was inferred significant.

\section{Conclusions}

Thus, our preliminary cross-sectional findings suggest that PPI use does not appear to considerably affect circulating ADMA in non-diabetic men with stable CAD. Whether novel mechanisms of adverse PPI effects on the vasculature can be translated into clinical conditions, requires validation in large well-designed studies.

Acknowledgments: This work was supported in part by a research grant (No. K/ZDS/003761) from the Jagiellonian University Medical College, Cracow, Poland. The publication of this paper was supported by the Faculty of Medicine, Jagiellonian University Medical College, Leading National Research Center (KNOW) 2012-2017.

Author Contributions: Olga Kruszelnicka conceived and designed the study, analyzed and interpreted data, and wrote the manuscript. Jolanta Świerszcz, Jacek Bednarek and Bernadeta Chyrchel contributed to data collection and analysis. Jadwiga Nessler and Andrzej Surdacki contributed to study design and discussion, and supervised the study. All authors read, critically revised and approved the final manuscript.

Conflicts of Interest: The authors declare no conflict of interest.

\section{Abbreviations}

$\begin{array}{ll}\text { ACEI } & \text { angiotensin-converting enzyme inhibitors } \\ \text { ADMA } & \begin{array}{l}\text { asymmetric dimethylarginine } \\ \text { analysis of covariance }\end{array} \\ \text { ANCOVA } & \text { analysis of variance } \\ \text { CAD } & \text { coronary artery disease } \\ \text { CYP } & \text { cytochrome P450 } \\ \text { DDAH-1 } & \text { type } 1 \text { dimethylarginine dimethylaminohydrolase } \\ \text { ELISA } & \text { enzyme-linked immunosorbent assay }\end{array}$




$\begin{array}{ll}\text { GFR } & \text { glomerular filtration rate } \\ \text { HDL } & \text { high-density lipoproteins } \\ \text { HO-1 } & \text { type } 1 \text { heme oxygenase } \\ \text { LDL } & \text { low-density lipoproteins } \\ \text { NADPH } & \text { nicotinamide adenine dinucleotide phosphate } \\ \text { NO } & \text { nitric oxide } \\ \text { PPI } & \text { proton pump inhibitors } \\ \text { PRMTs-I } & \text { type I protein-arginine } N \text {-methyltransferases } \\ \text { SD } & \text { standard deviation }\end{array}$

\section{References}

1. Ghebremariam, Y.T.; LePendu, P.; Lee, J.C.; Erlanson, D.A.; Slaviero, A.; Shah, N.H.; Leiper, J.; Cooke, J.P. Unexpected effect of proton pump inhibitors: Elevation of the cardiovascular risk factor asymmetric dimethylarginine. Circulation 2013, 128, 845-853. [CrossRef] [PubMed]

2. Schnabel, R.; Blankenberg, S.; Lubos, E.; Lackner, K.J.; Rupprecht, H.J.; Espinola-Klein, C.; Jachmann, N.; Post, F.; Peetz, D.; Bickel, C.; et al. Asymmetric dimethylarginine and the risk of cardiovascular events and death in patients with coronary artery disease: Results from the AtheroGene study. Circ. Res. 2005, 97, e53-e59. [CrossRef] [PubMed]

3. Meinitzer, A.; Seelhorst, U.; Wellnitz, B.; Halwachs-Baumann, G.; Boehm, B.O.; Winkelmann, B.R.; März, W. Asymmetrical dimethylarginine independently predicts total and cardiovascular mortality in individuals with angiographic coronary artery disease (the Ludwigshafen Risk and Cardiovascular Health study). Clin. Chem. 2007, 53, 273-283. [CrossRef] [PubMed]

4. Wang, Z.; Tang, W.H.; Cho, L.; Brennan, D.M.; Hazen, S.L. Targeted metabolomic evaluation of arginine methylation and cardiovascular risks: Potential mechanisms beyond nitric oxide synthase inhibition. Arterioscler. Thromb. Vasc. Biol. 2009, 29, 1383-1391. [CrossRef] [PubMed]

5. Ho, P.M.; Maddox, T.M.; Wang, L.; Fihn, S.D.; Jesse, R.L.; Peterson, E.D.; Rumsfeld, J.S. Risk of adverse outcomes associated with concomitant use of clopidogrel and proton pump inhibitors following acute coronary syndrome. JAMA 2009, 301, 937-944. [CrossRef] [PubMed]

6. Juurlink, D.N.; Gomes, T.; Ko, D.T.; Szmitko, P.E.; Austin, P.C.; Tu, J.V.; Henry, D.A.; Kopp, A.; Mamdani, M.M. A population-based study of the drug interaction between proton pump inhibitors and clopidogrel. CMAJ 2009, 180, 713-718. [CrossRef] [PubMed]

7. Charlot, M.; Ahlehoff, O.; Norgaard, M.L.; Jørgensen, C.H.; Sørensen, R.; Abildstrøm, S.Z.; Hansen, P.R.; Madsen, J.K.; Køber, L.; Torp-Pedersen, C.; et al. Proton-pump inhibitors are associated with increased cardiovascular risk independent of clopidogrel use: A nationwide cohort study. Ann. Intern. Med. 2010, 153, 378-386. [CrossRef] [PubMed]

8. Charlot, M.; Grove, E.L.; Hansen, P.R.; Olesen, J.B.; Ahlehoff, O.; Selmer, C.; Lindhardsen, J.; Madsen, J.K.; Køber, L.; Torp-Pedersen, C.; et al. Proton pump inhibitor use and risk of adverse cardiovascular events in aspirin treated patients with first time myocardial infarction: Nationwide propensity score matched study. BMJ 2011, 342, d2690. [CrossRef] [PubMed]

9. Goodman, S.G.; Clare, R.; Pieper, K.S.; Nicolau, J.C.; Storey, R.F.; Cantor, W.J; Mahaffey, K.W.; Angiolillo, D.J;; Husted, S.; Cannon, C.P.; et al. Association of proton pump inhibitor use on cardiovascular outcomes with clopidogrel and ticagrelor: Insights from the platelet inhibition and patient outcomes trial. Circulation 2012, 125, 978-986. [CrossRef] [PubMed]

10. Kwok, C.S.; Jeevanantham, V.; Dawn, B.; Loke, Y.K. No consistent evidence of differential cardiovascular risk amongst proton-pump inhibitors when used with clopidogrel: Meta-analysis. Int. J. Cardiol. 2013, 167, 965-974. [CrossRef] [PubMed]

11. Shih, C.J.; Chen, Y.T.; Ou, S.M.; Li, S.Y.; Chen, T.J.; Wang, S.J. Proton pump inhibitor use represents an independent risk factor for myocardial infarction. Int. J. Cardiol. 2014, 177, 292-297. [CrossRef] [PubMed]

12. Shah, N.H.; LePendu, P.; Bauer-Mehren, A.; Ghebremariam, Y.T.; Iyer, S.V.; Marcus, J.; Nead, K.T.; Cooke, J.P.; Leeper, N.J. Proton pump inhibitor usage and the risk of myocardial infarction in the general population. PLoS ONE 2015, 10, e0124653. [CrossRef] [PubMed] 
13. Agewall, S.; Cattaneo, M.; Collet, J.P.; Andreotti, F.; Lip, G.Y.; Verheugt, F.W.; Huber, K.; Grove, E.L.; Morais, J.; Husted, S.; et al. Expert position paper on the use of proton pump inhibitors in patients with cardiovascular disease and antithrombotic therapy. Eur. Heart J. 2013, 34, 1708-1713. [CrossRef] [PubMed]

14. Melloni, C.; Washam, J.B.; Jones, W.S.; Halim, S.A.; Hasselblad, V.; Mayer, S.B.; Heidenfelder, B.L.; Dolor, R.J. Conflicting results between randomized trials and observational studies on the impact of proton pump inhibitors on cardiovascular events when coadministered with dual antiplatelet therapy: Systematic review. Circ. Cardiovasc. Qual. Outcomes 2015, 8, 47-55. [CrossRef] [PubMed]

15. Ghebremariam, Y.T.; Cooke, J.P.; Khan, F.; Thakker, R.N.; Chang, P.; Shah, N.H.; Nead, K.T.; Leeper, N.J. Proton pump inhibitors and vascular function: A prospective cross-over pilot study. Vasc. Med. 2015, 20, 309-316. [CrossRef] [PubMed]

16. Wang, D.; Gill, P.S.; Chabrashvili, T.; Onozato, M.L.; Raggio, J.; Mendonca, M.; Dennehy, K.; Li, M.; Modlinger, P.; Leiper, J.; et al. Isoform-specific regulation by $N^{\mathrm{G}}, N^{\mathrm{G}}$-dimethylarginine dimethylaminohydrolase of rat serum asymmetric dimethylarginine and vascular endothelium-derived relaxing factor/NO. Circ. Res. 2007, 101, 627-635. [CrossRef] [PubMed]

17. Lind, L.; Ingelsson, E.; Kumar, J.; Syvänen, A.C.; Axelsson, T.; Teerlink, T. Genetic variation in the dimethylarginine dimethylaminohydrolase 1 gene (DDAH1) is related to asymmetric dimethylarginine (ADMA) levels, but not to endothelium-dependent vasodilation. Vasc. Med. 2013, 18, 192-199. [CrossRef] [PubMed]

18. Seppälä, I.; Kleber, M.E.; Lyytikäinen, L.P.; Hernesniemi, J.A.; Mäkelä, K.M.; Oksala, N.; Laaksonen, R.; Pilz, S.; Tomaschitz, A.; Silbernagel, G.; et al. Genome-wide association study on dimethylarginines reveals novel AGXT2 variants associated with heart rate variability but not with overall mortality. Eur. Heart J. 2014, 35, 524-531. [CrossRef] [PubMed]

19. Lüneburg, N.; Lieb, W.; Zeller, T.; Chen, M.H.; Maas, R.; Carter, A.M.; Xanthakis, V.; Glazer, N.L.; Schwedhelm, E.; Seshadri, S.; et al. Genome-wide association study of L-arginine and dimethylarginines reveals novel metabolic pathway for symmetric dimethylarginine. Circ. Cardiovasc. Genet. 2014, 7, 864-872. [CrossRef] [PubMed]

20. Delles, C.; Schneider, M.P.; John, S.; Gekle, M.; Schmieder, R.E. Angiotensin converting enzyme inhibition and angiotensin ii $\mathrm{AT}_{1}$-receptor blockade reduce the levels of asymmetrical $N^{\mathrm{G}}, N^{\mathrm{G}}$-dimethylarginine in human essential hypertension. Am. J. Hypertens. 2002, 15, 590-593. [CrossRef]

21. Hetzel, S.; DeMets, D.; Schneider, R.; Borzak, S.; Schneider, W.; Serebruany, V.; Schröder, H.; Hennekens, C.H. Aspirin increases nitric oxide formation in chronic stable coronary disease. J. Cardiovasc. Pharmacol. Ther. 2013, 18, 217-221. [CrossRef] [PubMed]

22. Serban, C.; Sahebkar, A.; Ursoniu, S.; Mikhailidis, D.P.; Rizzo, M.; Lip, G.Y.; Kees Hovingh, G.; Kastelein, J.J.; Kalinowski, L.; Rysz, J.; et al. A systematic review and meta-analysis of the effect of statins on plasma asym metric dimethylarginine concentrations. Sci. Rep. 2015, 5, 9902. [CrossRef] [PubMed]

23. Krempl, T.K.; Maas, R.; Sydow, K.; Meinertz, T.; Böger, R.H.; Kähler, J. Elevation of asymmetric dimethylarginine in patients with unstable angina and recurrent cardiovascular events. Eur. Heart J. 2005, 26, 1846-1851. [CrossRef] [PubMed]

24. Schulze, F.; Lenzen, H.; Hanefeld, C.; Bartling, A.; Osterziel, K.J.; Goudeva, L.; Schmidt-Lucke, C.; Kusus, M.; Maas, R.; Schwedhelm, E.; et al. Asymmetric dimethylarginine is an independent risk factor for coronary heart disease: Results from the multicenter Coronary Artery Risk Determination investigating the Influence of ADMA Concentration (CARDIAC) study. Am. Heart J. 2006, 152. [CrossRef] [PubMed]

25. Napora, M.; Graczykowska, A.; Próchniewska, K.; Zdrojewski, Z.; Całka, A.; Górny, J.; Stompór, T. Relationship between serum asymmetric dimethylarginine and left ventricular structure and function in patients with end-stage renal disease treated with hemodialysis. Pol. Arch. Med. Wewn. 2012, 122, 226-234. [PubMed]

26. Teerlink, T.; Luo, Z.; Palm, F.; Wilcox, C.S. Cellular ADMA: Regulation and action. Pharmacol. Res. 2009, 60, 448-460. [CrossRef] [PubMed]

27. Becker, J.C.; Grosser, N.; Waltke, C.; Schulz, S.; Erdmann, K.; Domschke, W.; Schröder, H.; Pohle, T. Beyond gastric acid reduction: Proton pump inhibitors induce heme oxygenase- 1 in gastric and endothelial cells. Biochem. Biophys. Res. Commun. 2006, 345, 1014-1021. [CrossRef] [PubMed] 
28. Böger, R.H.; Sydow, K.; Borlak, J.; Thum, T.; Lenzen, H.; Schubert, B.; Tsikas, D.; Bode-Böger, S.M. LDL cholesterol upregulates synthesis of asymmetrical dimethylarginine in human endothelial cells: Involvement of S-adenosylmethionine-dependent methyltransferases. Circ. Res. 2000, 87, 99-105. [CrossRef] [PubMed]

29. Ito, A.; Tsao, P.S.; Adimoolam, S.; Kimoto, M.; Ogawa, T.; Cooke, J.P. Novel mechanism for endothelial dysfunction: Dysregulation of dimethylarginine dimethylaminohydrolase. Circulation 1999, 99, 3092-3095. [CrossRef] [PubMed]

30. Palm, F.; Onozato, M.L.; Luo, Z.; Wilcox, C.S. Dimethylarginine dimethylaminohydrolase (DDAH): Expression, regulation, and function in the cardiovascular and renal systems. Am. J. Physiol. Heart Circ. Physiol. 2007, 293, H3227-H3245. [CrossRef] [PubMed]

31. Kieboom, B.C.; Kiefte-de Jong, J.C.; Eijgelsheim, M.; Franco, O.H.; Kuipers, E.J.; Hofman, A.; Zietse, R.; Stricker, B.H.; Hoorn, E.J. Proton pump inhibitors and hypomagnesemia in the general population: A population-based cohort study. Am. J. Kidney Dis. 2015, 66, 775-782. [CrossRef] [PubMed]

32. Attwood, S.E.; Ell, C.; Galmiche, J.P.; Fiocca, R.; Hatlebakk, J.G.; Hasselgren, B.; Långström, G.; Jahreskog, M.; Eklund, S.; Lind, T.; et al. Long-term safety of proton pump inhibitor therapy assessed under controlled, randomised clinical trial conditions: Data from the SOPRAN and LOTUS studies. Aliment. Pharmacol. Ther. 2015, 41, 1162-1174. [CrossRef] [PubMed]

33. Würtz, M.; Grove, E.L.; Kristensen, S.D.; Hvas, A.M. The antiplatelet effect of aspirin is reduced by proton pump inhibitors in patients with coronary artery disease. Heart 2010, 96, 368-371. [CrossRef] [PubMed]

34. Adamopoulos, A.B.; Sakizlis, G.N.; Nasothimiou, E.G.; Anastasopoulou, I.; Anastasakou, E.; Kotsi, P.; Karafoulidou, A.; Stergiou, G.S. Do proton pump inhibitors attenuate the effect of aspirin on platelet aggregation? A randomized crossover study. J. Cardiovasc. Pharmacol. 2009, 54, 163-168. [CrossRef] [PubMed]

35. Uno, T.; Niioka, T.; Hayakari, M.; Yasui-Furukori, N.; Sugawara, K.; Tateishi, T. Absolute bioavailability and metabolism of omeprazole in relation to CYP2C19 genotypes following single intravenous and oral administrations. Eur. J. Clin. Pharmacol. 2007, 63, 143-149. [CrossRef] [PubMed]

36. Barter, Z.E.; Tucker, G.T.; Rowland-Yeo, K. Differences in cytochrome p450-mediated pharmacokinetics between Chinese and Caucasian populations predicted by mechanistic physiologically based pharmacokinetic modelling. Clin. Pharmacokinet. 2013, 52, 1085-1100. [CrossRef] [PubMed]

37. Krajčíová, L.; Petrovič, R.; Déžiová, L.; Chandoga, J.; Turčáni, P. Frequency of selected single nucleotide polymorphisms influencing the warfarin pharmacogenetics in Slovak population. Eur. J. Haematol. 2014, 93, 320-328. [CrossRef] [PubMed]

38. Kruszelnicka, O.; Surdacki, A.; Golay, A. Differential associations of angiographic extent and severity of coronary artery disease with asymmetric dimethylarginine but not insulin resistance in non-diabetic men with stable angina: A cross-sectional study. Cardiovasc. Diabetol. 2013, 12, 145. [CrossRef] [PubMed]

39. Kruszelnicka-Kwiatkowska, O.; Surdacki, A.; Goldsztajn, P.; Matysek, J.; Piwowarska, W.; Golay, A. Relationship between hyperinsulinemia and angiographically defined coronary atherosclerosis in non-diabetic men. Diabetes Metab. 2002, 28, 305-309. [PubMed]

40. Sullivan, D.R.; Marwick, T.H.; Freedman, S.B. A new method of scoring coronary angiograms to reflect extent of coronary atherosclerosis and improve correlation with major risk factors. Am. Heart J. 1990, 119, 1262-1267. [CrossRef]

(C) 2016 by the authors; licensee MDPI, Basel, Switzerland. This article is an open access article distributed under the terms and conditions of the Creative Commons Attribution (CC-BY) license (http://creativecommons.org/licenses/by/4.0/). 